\title{
Energia: um conceito unificador em sucessivas situações de estudo
}

\author{
Maria Cristina Pansera Araújo* \\ Eva Teresinha Oliveira Boff*
}

Resumo: Este trabalho sistematiza seis situações de estudo (SE) produzidas coletivamente pelo Gipec-Unijuí e pelos professores das redes de ensino de Ijuí. Essas redes focalizam o conceito unificador energia (ANGOTTI, 1991) e suas relações com a sustentabilidade. O conceito foi evidenciado, significado e complexificado nas diferentes SE de modo evolutivo (VIGOTSKI, 2000), já que a palavra constitui o pensamento. A elaboração das SE compreendeu, ainda, a identificação de outros conceitos científicos interrelacionados, contemplando procedimentos, valores, atitudes e perspectiva ética no trato dos aspectos vivenciados e da compreensão esperada a partir das ciências da natureza e suas tecnologias. A organização das SE contempla atividades, realizadas na escola e/ou fora delas, com observações estruturadas em objetivos e conteúdos com registros, sistematizações e análise do trabalho desenvolvido, constituindo-se em espaços de formação pela pesquisa.

Palavras-chave: Situação de estudo; Conceito científico; Energia.

Abstract: This study classifies six Study Situations produced collectively by Gipec-Unijuí and the teachers of in the education networks of Ijui. They focus on the unifying concept energy (ANGOTTI, 1991) and its relationship to sustainability. The

Professora do Departamento de Ciências da Vida e do Mestrado em Educação nas Ciências-UNIJUI/RS. Doutora em Genética pela UFRGS. E-mail: pansera@unijui. edu.br.

** Professora vinculada ao Departamento de Ciências da Vida da UNIJUI, Doutora em Educação em Ciências pela UFRGS. E-mail: evaboff@unijui.edu.br. 
concept was evidenced in the different meaning and complexified Study Situation mode process (VIGOTSKI, 2000), since the word is thought. The development of Study Situation understood yet, the identification of other scientific concepts, and encompassing interrelated procedures, values, attitudes and ethical perspective in dealing with the issues experienced and understanding expected from the natural sciences and technologies. The organization of SE includes activities conducted in school and / or outside them, with comments under objectives and content with records, systematization and analysis of the work, being in training for space research.

Keywords: Study Situations; Scientific concepts; Energy.

\section{Introdução}

A ciência é uma criação humana dinâmica, cujos temas são tratados de forma crítica e reflexiva buscando as interações com a sobrevivência e a qualidade de vida. Documentos da UNESCO (2008) apontam que o processo educativo deveria ser "reformulado para o desenvolvimento sustentável", um objetivo decisivo da relação "homem-natureza". Essa perspectiva pode ser abordada de diferentes maneiras no ensino, já que os PCNs (BRASIL, 1998 e 1999), sinalizam para a superação do ensino tradicional pelo incremento de atividades dinamizadoras e articuladoras das práticas no Ensino de Ciências, por intermédio de aprendizados escolares significativos e socialmente relevantes. Novas propostas curriculares articulam os conceitos científicos das Ciências da Natureza e suas Tecnologias, a partir da comunidade escolar, buscando integrar os fenômenos cotidianos ao conhecimento científico sistematizado. Em especial, nessa área da Educação Básica, o ensino tem sido alvo de inúmeros estudos, questionamentos e proposições, entre os quais, vale citar a sensibilização para a formação de uma consciência, em que "o saber que sabe é o fundamento" (VIGOTSKI, 2000, p. 65), construído a partir de múltiplas situações. Nesse contexto, o desenvolvimento 
sustentável ou da sustentabilidade ambiental impõe-se nos diferentes espaços de convivência e aprendizagens humanas, com repercussões na escola e na formação de professores.

Uma das questões amplamente debatidas e que tem influenciado a educação ambiental para o desenvolvimento sustentável se refere ao uso de energia a partir de fontes renováveis. Considerando essa perspectiva e também que o conceito de energia perpassa por diversos conhecimentos da área das Ciências da Natureza, esse se constitui numa referência de análise, por ser constante e fundamental nos diferentes componentes curriculares.

Embora energia seja um conceito fundamental da Física, em que a conservação e a transformação são princípios inerentes, ele perpassa todos os componentes curriculares em qualquer nível de ensino. A primeira lei da termodinâmica descreve a conversão de uma forma de energia em outra, sem poder ser criada ou destruída, e a segunda lei estabelece que em todas as trocas e conversões de energia, o potencial do estado final será sempre menor que o do estado inicial. Bittencourt (2005) argumenta que a vida em nosso planeta só é possível por meio de processos de transformações de energia, já que os seres vivos têm como atributos básicos: crescimento, metabolismo, movimento, reprodução. Se a vida só se mantém graças às trocas constantes de energia, é necessário compreender que ela não pode ser desperdiçada pelos seres humanos.

Baseando-se nessa linha de pensamento, o presente texto aborda uma breve sistematização de uma inovação curricular denominada Situação de Estudo (SE), que tem como objetivo contribuir à formação de cidadãos conscientes e críticos, quanto às relações de energia, de ambiente e de sustentabilidade. 


\section{O contexto do estudo}

A proposta de organização curricular SE tem origem no Grupo Interdepartamental de Pesquisa sobre Educação em Ciências (Gipec-Unijuí) e é produzida, elaborada e desenvolvida em parceria colaborativa com a SMEd-Ijuí, escolas da $36^{a}$ Coordenadoria Regional de Educação ( $\left.36^{\mathrm{a}} \mathrm{CRE}\right)$ e Centro de Educação Francisco de Assis. Algumas açôes foram desenvolvidas a partir de reuniôes de planejamento e de estudo envolvendo professores de ciências da educação básica, licenciandos (bolsistas de pesquisa, extensão e voluntários) e professores universitários. As SE, produzidas coletivamente e desenvolvidas nas escolas de Educação Básica, são conceitualmente ricas para as diversas ciências; consideram a vivência dos estudantes; assumem características disciplinares, interdisciplinares e contextuais; além de articularem a formação inicial e continuada de professores (ARAÚJO $e t a l$., 2005). A partir de 2000, diversas SE foram elaboradas e desenvolvidas na Educação Básica, enfatizando os conceitos tratados e as possibilidades de significá-los cientificamente, a partir de relaçóes interdisciplinares adequadas aos estudantes de $5^{\mathrm{a}}$ a $8^{\mathrm{a}}$ séries do Ensino Fundamental.

Destaca-se neste texto um conjunto de SE, nas quais a palavra energia foi expressa e evidenciada nas suas diferentes formas (elétrica, luminosa, química, potencial, cinética, nuclear, mecânica, por exemplo), transformações, conservação e relações, mostrando a necessidade de discutir essa questão de maneira sistemática na Educação Básica. Ao desenvolver as sucessivas SE, o conceito energia foi complexificado, constituindo-se numa consciência crítica frente às questôes ambientais e aos conteúdos disciplinares para o ensino de Ciências. O conceito energia e suas relações com a sustentabilidade foram evidenciados e significados, em diferentes contextos em concordância com Vigotski (2000), já que a palavra constitui o pensamento e, portanto, cria novas possibilidades de significação e de compreensão. 


\section{O significado de energia no contexto das situações de estudo}

Embora energia seja um conceito tradicionalmente trabalhado pela disciplina de Física ou pelos professores de Ciências do Ensino Fundamental, reservado apenas para a $8^{\mathrm{a}}$ série, ele constitui-se em conceito unificador das diversas SE, tanto na disciplina de Ciências quanto nas disciplinas das diferentes áreas do conhecimento. A abordagem desenvolvida mostra que, tanto na Biologia quanto na Química e Física, o significado expresso é o mesmo, porém, em diferentes formas, é conservado, transformado e transportado. Também, a elaboração das SE além de focalizar conceitos científicos, a exemplo das diferentes formas de energia, prioriza sua significação a partir da valorização de procedimentos, valores, atitudes na perspectiva ética considerando aspectos importantes a serem tratados do ponto de vista das ciências da natureza e suas tecnologias. A organização das SE contempla atividades, realizadas na escola e/ou fora delas, com observaçóes estruturadas em objetivos e conteúdos com registros, sistematizações e análise do trabalho desenvolvido, constituindo-se em espaços de formação pela pesquisa.

A questão energética é uma preocupação atual. O conceito energia, embora pouco compreendido, tornou-se significativo para os seres humanos pela sua presença constante no cotidiano. Isto suscitou a discussão e a sistematização desse conceito, em sucessivas SE, para construir maior consciência ambiental à medida que o mesmo evolui, e é apropriado pelos estudantes, já que, "na medida em que o uso da palavra ou conceito aparece em diversos contextos, os estudantes vão criando novos significados e o conceito vai evoluindo, conforme pensamento de Vigotski” (BOFF et al., 2004, p. 297).

A palavra energia é identificada como um dos quatro conceitos unificadores (transformação, regularidade, energia e escala), que transitam pelas Ciências da Natureza. As pesquisas de Angotti (1991) e Auth (2000) mostraram que os conceitos 
unificadores podem constituir um elo articulador e facilitador de aprendizagem entre os diferentes componentes curriculares e áreas do conhecimento, que ultrapassam as barreiras da fragmentação de saberes, sem descartar os aprofundamentos necessários à especificidade de cada área das Ciências da Natureza e suas Tecnologias. Dessa forma, o conceito unificador energia constitui-se num elo entre as ciências contemplando a interdisciplinaridade e abrindo caminho para uma visão mais abrangente, contextualizada e crítica dos problemas socioambientais, discutidos em sala de aula. Nas seis SE descritas, a seguir, o conceito energia e outros correlacionados são abordados de maneira que possa integrar a realidade dos estudantes, oportunizando que eles se manifestem, dando suas opiniões e fazendo parte da construção do conhecimento de modo a evoluir com base no conhecimento da ciência já estruturado (BOFF, et al., 2009).

\section{Situações de estudo desenvolvidas no contexto das escolas de Ensino Fundamental}

As SE desenvolvidas e sistematizadas pelo grupo de professores do Gipec-Unijuí e SMEd-Ijuí para o Ensino Fundamental ( $5^{\mathrm{a}}$ a 8 séries) são: 1-Estudo de uma propriedade/empreendimento rural: organização do espaço e dos recursos naturais (FABER et al., 2004); 2- Estudo de uma microbacia hidrográfica: ocupação do espaço e biodiversidade (PANSERA; FERREIRA; BIANCHI, 2002); 3- Ser humano e ambiente: percepção e interação (AUTH; MELLER, 2005); 4-Alimentos - produção e consumo (BOFF; HAMES; FRISON, 2006); 5- Geração e gerenciamento dos residuos sólidos provenientes das atividades humanas (GIPEC, 2002); 6- Origem e transformação da energia na biosfera (FRONER et al., 2005). Estas SE, descritas a seguir, evidenciam a significação do conceito energia e as possibilidades de sua complexificação em diferentes contextos. Trata-se de uma produção coletiva que 
envolve professores da universidade, de escola básica e em informação inicial. A palavra energia é destacada nas SE para chamar atenção quanto ao seu uso em diversos contextos.

\section{Estudo de propriedade/empreendimento rural: organização do espaço e dos recursos naturais.}

Esta SE foi desenvolvida em turmas de quinta série do Ensino Fundamental em escolas municipais de Ijuí. A observação de uma propriedade rural possibilitou estabelecer uma reflexão geral sobre os problemas ambientais locais e globais (disponibilidade e potabilidade da água, agrotóxicos, fertilizantes, poluição, contaminação, produção de lixo, ...), incentivando os estudantes a desenvolverem uma nova consciência sobre suas próprias atuações, e as consequências das ações individuais e coletivas para o ambiente. A identificação e aprendizagem de alguns conceitos científicos, tais como: diversidade animal e vegetal; ecossistema, agroecossistema, seres vivos e não vivos, espaço, movimento, energia, matéria, substância, tipos e composição química do solo, possibilitam compreender melhor a organização do espaço e dos recursos naturais na propriedade rural em seus diferentes aspectos, assim como a sustentabilidade. Se a sustentabilidade ambiental é relativa aos impactos de atividades humanas sobre o ambiente, a produção primária, fornecida pela natureza, é a base que viabiliza a existência humana (VAN BELLEN, 2005), bem como o tipo de manejo do ecossistema e do agroecossistema escolhido. Em cada espaço da propriedade/empreendimento rural, existe algum tipo de energia sendo usada para manter, tanto os seres vivos quanto as funções propostas pela sociedade humana, como a energia luminosa proveniente do sol, a eólica, a das rodas de água, a elétrica resultante de baterias ou eletrificação rural, a mecânica, a cinética, a potencial.

Outro enfoque desta SE é a retomada da história dos antepassados que viviam ou ainda vivem na propriedade, os tipos de tecnologias utilizadas anteriormente e as emergentes, além 
da renovação e da eficiência do uso da energia, em cada local, atualmente. $\mathrm{O}$ aproveitamento das fontes de energia disponíveis cria uma integração das mesmas, que pode aumentar sua eficiência. Nesse contexto, ainda vale lembrar que um dos objetivos do empreendimento rural é a produção de alimentos (de origem vegetal e/ou animal), de fibras e de outras matérias-primas em qualidade e quantidade suficientes para a sociedade humana. Essa produção deveria ser ecologicamente correta, sem contaminar o ambiente, nem exercer pressão inadequada sobre os recursos naturais, considerando os aspectos relacionados à equidade social, e às tecnologias sustentáveis que se instauraram ao longo do tempo (BITTENCOURT, 2005). É interessante, também, revisar as tecnologias utilizadas noutros países, para verificar as matrizes energéticas disponíveis e adequadas ao desenvolvimento sustentável (REIS; SILVEIRA et al., 2001), e que poderão ser aproveitadas nos empreendimentos rurais em estudo, como alternativas a serem analisadas pelos estudantes para a construção de novas soluções aos problemas identificados.

\section{Estudo de uma microbacia hidrográfica: ocupação do espaço e biodiversidade}

Esta SE é sugerida para sexta série do Ensino Fundamental e enfatiza o estudo de um ecossistema, de ciclos biogeoquímicos, da biodiversidade, das formas de interação e das relações de dependência dos seres vivos entre si e desses com os fatores abióticos do ambiente. A relação trófica entre os diversos seres vivos começa com a captação da radiação solar pelos produtores, que a transformam em energia cinética e potencial. Tais tipos de energia são usados para garantir vida e, formar as substâncias constitutivas dos seres vivos dos outros níveis tróficos de cadeias alimentares, bem como dissipar o resultado das transformações energéticas sob a forma de calor. $\mathrm{O}$ equilíbrio dos ecossistemas começa com a energia solar e depende de outros fatores como os ciclos biogeoquímicos. 
Por isso, é preciso conscientizar os alunos e instaurar nas escolas a discussão sobre essa questão: a sustentabilidade com enfoque ambiental. Nas discussões, é importante sublinhar que toda agressão antrópica causa o desequilíbrio, alterando todo o ecossistema e, consequentemente, a sustentabilidade de sua comunidade. No entanto, a atividade humana pode interferir nessas relações com a exploração abusiva, impedindo, assim, que o ecossistema se recomponha. Um indicativo da ação humana sobre o ecossistema, que reforça a ideia da insustentabilidade do desenvolvimento de nossa sociedade, é a redução da quantidade de solo fértil em vários locais do mundo (CANTO, 1999), seja pela super-exploração (com mais de duas safras por ano), seja pela ocupação de espaços com a construção de cidades. Além disso, o uso da água para irrigação, a drenagem das nascentes e a construção de hidroelétricas alteram substancialmente a paisagem.

\section{Ser humano e ambiente: percepção e interação}

A SE, com foco no ser humano e no ambiente, foi produzida e desenvolvida na sétima série do Ensino Fundamental. A interação entre os seres e o ambiente é o que permite ou não a sobrevivência dos diferentes seres vivos e isso envolve a luz, o som ou o calor mediante a absorção, dissipação e trocas de energia. Nessa interação, do ser humano com o ambiente, as transformações de uma forma de energia em outra ocorrem na interação com a matéria em cada um dos cinco órgãos do sentido. Por exemplo, é na interação dos cones e bastonetes que a energia luminosa se transforma em energia elétrica. Essa é a condição necessária para que o cérebro possa reconhecer e processar as informações recebidas do ambiente.

A poluição sonora, por exemplo, está diretamente relacionada à energia da onda sonora. Isso significa que os sons produzidos por diversas fontes podem ter amplitudes variadas e podem "carregar" quantidades diferentes de energia. Os sons excessivamente intensos, além de desagradáveis à audição, são 
prejudiciais, ainda mais se o indivíduo está exposto diariamente, por períodos prolongados, ao som muito intenso. Isso pode acelerar a destruição das células ciliadas responsáveis pela transdução da energia sonora em elétrica, e comprometer a audição, levando a surdez permanente, pois essas células não se regeneram. Nos últimos tempos, o excesso de ruído, principalmente nas grandes cidades, se intensificou.

Segundo dados da Diretoria de Qualidade Ambiental, a poluição sonora não afeta somente a audição, mas ocasiona distúrbios do sono, estresse, dores de cabeça, alergias, distúrbios digestivos, falta de concentração, aumento do batimento cardíaco, entre outros. A solução para esse problema foi a criação do Programa Silêncio, cujo controle compete ao IBAMA e que tem como um dos cinco objetivos "incentivar a fabricação e uso de máquinas, motores, equipamentos e dispositivos que emitam menor intensidade de ruído quando de sua utilização na indústria, veículos em geral, construção civil, utilidades domésticas, etc ${ }^{1}$.”

\section{Alimentos - produção e consumo}

O planejamento dessa SE, com foco na alimentação humana, também foi pensado para sétima série do Ensino Fundamental. Foram identificados e (re)significados conceitos científicos na perspectiva de compreender o alimento "como fonte de matéria e de energia, bem como as transformações necessárias para uma boa nutrição e saúde" (BOFF; FRISON; KINALSKI, p. 288, 2004). As funções básicas dos alimentos e a alimentação humana constituem-se em eixos norteadores da SE, com ênfase na energia necessária para possibilitar as transformações que permitam a manutenção da vida, bem como garantir a eficácia das substâncias

O PROGRAMA NACIONAL DE EDUCAÇÃO E CONTROLE DA POLUIÇÃO SONORA - SILÊNCIO foi instituído pela Resolução CONAMA nº 2, de 8/3/90 considerando a necessidade de estabelecer normas, métodos e ações para controlar o ruído excessivo que interfere na saúde e bem estar da população. Disponível em: http://www.ibama.gov.br/silencio/home.htm Acesso em: 20 de jan. 2008. 
constitutivas das células, dos tecidos, dos órgãos e dos sistemas do organismo.

Essas substâncias, do ponto de vista nutricional, são denominadas nutrientes. Portanto, compreender as funções e propriedades de nutrientes como: água, vitaminas, sais minerais, carboidratos, proteínas, lipídios, entre outros, possibilita compreender conceitos científicos a partir de questões da vivência dos estudantes. A água é o meio pelo qual, praticamente, todas as substâncias nutrientes interagem, estando, por isso, sempre presente nos alimentos e em sua veiculação no organismo (BOFF et al., 2006).

Entre os nutrientes mencionados, alguns são reconhecidos em contextos diversos da vida, na sociedade, como "altamente energéticos" (a exemplo das massas e das gorduras), enquanto outros são categorizados como sendo de "baixo teor energético" (a exemplo de frutas e verduras). Tanto um quanto outro grupo sozinho, não supre as necessidades nutricionais, mesmo que se constituam em nutrientes essenciais à dieta. Abordagens didáticas, em sala de aula, sobre a maneira como alguns alimentos são produzidos, a exemplo do queijo e do pão, possibilitam desenvolver conceitos relativos às áreas de Química, de Física e de Biologia, de modo a produzir aprendizagens significativas para os estudantes tais como: constituição e transformações básicas dos alimentos; as interações entre substâncias; a influência do pH na solubilidade de certas substâncias; os microorganismos que contribuem às transformações envolvidas no processamento e na decomposição dos alimentos; o processo digestivo e a qualidade da alimentação.

Praticamente em todas as questões discutidas existe alguma forma de energia envolvida, de modo que esse conceito, na medida em que é utilizado em diversos contextos, produz diferentes níveis de compreensão. Na espécie humana, por exemplo, os alimentos sofrem combustão no organismo - o calor produzido é útil para manter a temperatura do corpo e, o "valor calórico" diz respeito apenas à energia que os nutrientes podem fornecer. A energia química, obtida a partir oxidação dos nutrientes, é 
usada para todas as funções do organismo na forma de ATP (adenosina trifosfatada), nas diferentes células dos seres vivos (BOFF; FRISON; KINALSKI, 2004). Foram realizadas atividades experimentais envolvendo a queima de alimentos em que a quantidade de energia liberada é medida no decorrer do processo de combustão. Isto possibilitou a produção de significados mais complexos para a palavra energia, tais como: interação do alimento (combustível) com o oxigênio, evidenciando a produção de novas sustâncias com diferentes potenciais energéticos; aumento de energia cinética indicada pelo aumento da temperatura da água; o calor específico, a relação energia e trabalho, entre outros. A intercomplementaridade e interrelação do conceito energia, nas Ciências da Natureza e suas Tecnologias (como foi implementado nessa SE), permitem a evolução conceitual efetiva.

\section{Geração e gerenciamento dos resíduos sólidos provenientes das atividades humanas}

A significação dos conceitos de Física e de Química, normalmente desenvolvidos na oitava série do Ensino Fundamental, foi possível graças ao desenvolvimento dessa SE, na interação com os conceitos biológicos. $\mathrm{O}$ mau gerenciamento dos recursos energéticos e sua utilização desmedida têm causado muitos transtornos ao ambiente, que nem sempre são evidentes. A produção exagerada de resíduos sólidos e o não reaproveitamento desses podem ser considerados desperdício de energia e de material.

Essa SE aborda a composição química dos materiais que compõem os resíduos sólidos proveniente das atividades humanas e, a compostagem - processo de transformação de resíduos sólidos tais como folhas, cascas, fezes de bovinos, ovinos, aves, por exemplo -, em que seres vivos decompositores (necrófagos, detritívoros e microdecompositores) estão envolvidos diretamente. $\mathrm{O}$ aumento da temperatura, que decorre das transformações da matéria orgânica e do metabolismo, envolve energia cinética, potencial e térmica. Esta última é responsável pelo 
aquecimento do sistema, que eleva a temperatura da compostagem. Desse modo, resultam do processo, o biogás e o composto, fontes energéticas tradicionais, também chamada de biomassa. Essa é composta por matéria orgânica resultante de processos biológicos, envolvendo a captura da energia solar e posteriores transformações, constituindo rico potencial energético, além de ser renovável.

Entre as diversas formas de biomassa podem-se citar a madeira, as plantas, os restos de alimentos, além de excrementos de animais, esgoto sanitário, águas residuais industriais e diversos outros elementos ou resíduos de composição orgânica. Esses produtos, ao passarem por processos de conversão como a combustão, a digestão por microorganismos, a fermentação, a reação química e outros, geram energia calórica ou biogás (OLIVEIRA, 2007). O biogás pode ser coletado por meio de um biodigestor: estruturas fechadas com tubulação longa para captação do gás metano residual produzido no processo de compostagem dos resíduos úmidos, provenientes do metabolismo dos seres humanos, de animais e de plantas. $\mathrm{O}$ metano pode ser aproveitado para a geração de energia. Os biodigestores capturam o metano antes que ele se torne um problema e o armazenam para posterior aproveitamento, como o uso em aquecimento de ambientes ou como gás de cozinha.

\section{Origem e transformação da energia na biosfera}

O desenvolvimento dessa SE também ocorreu na oitava série do Ensino Fundamental. A importância do Sol para a vida na Terra parece constituir-se numa questão muito simples, mas que pode ser enfocada no Ensino Fundamental (EF) na perspectiva de inter-relacionar os conceitos biológicos, físicos e químicos. Desse modo, a partir de uma entrevista com a comunidade, realizada pelos estudantes da oitava série do EF de uma escola municipal, foi questionada a importância da existência ou não do Sol para a vida na Terra, e suas consequências. A resposta mais 
manifestada foi "a vida não existiria”. Diante disso, a professora discutiu com os estudantes as respostas, relacionando-as com os temas da Biologia já trabalhados nas séries anteriores.

A fotossíntese, por exemplo, um fenômeno biológico, responsável pela vida na Terra, absorve energia luminosa solar pela clorofila (um pigmento de cor verde), presente nas células vegetais, sendo considerada uma "antena coletora de luz", cuja função é participar na transformação de: gás carbônico $\left(\mathrm{CO}_{2}\right)$ e água $\left(\mathrm{H}_{2} \mathrm{O}\right)$ em glicose $\left(\mathrm{C}_{6} \mathrm{H}_{12} \mathrm{O}_{6}\right)$ e oxigênio $\left(\mathrm{O}_{2}\right)$. Do processo de fotossíntese, resulta o oxigênio $\left(\mathrm{O}_{2}\right)$ e o armazenamento de energia química na forma de amido, na planta. Após a ingestão e digestão das sementes, flores, frutos, caules ou raízes, pelos animais, a glicose disponibilizada tem duas funçôes fundamentais: 1) constituir compostos tais como, outros glicídios, lipídios, proteínas e ácidos nucleicos, que permitem a organização estrutural e o crescimento dos seres vivos; 2) fornecer energia para o metabolismo. A glicose, na respiração dos seres vivos (plantas, animais, bactérias, fungos e protistas), é "queimada lentamente" numa reação de oxidação, que armazena energia (Adenosina Trifosfatada - ATP) necessária às transformações dos compostos químicos para garantir a vida. Após absorver e armazenar uma pequena parcela da energia_solar que chega ao nosso planeta, as plantas e algas fornecem parte dela aos outros seres vivos, que se alimentarão delas, e utilizarão parte desse alimento em suas funções vitais.

A incorporação de conhecimentos relacionados a esses fenômenos (fotossíntese e respiração) interdependentes e o papel da energia nesses dois processos é constantemente ressignificado. Os estudos da fotossíntese permitem entender melhor o processo de formação de biomassa como fonte energética, visando à sustentabilidade. Durante o processo de decomposição da planta pelos microorganismos, a energia química acumulada será novamente disponibilizada, ou então, constituirá os combustíveis fósseis, se as condições forem favoráveis. 
Todos os conceitos abordados nas SE, mediados pelo professor, precisam evoluir na compreensão dos estudantes, de modo que o saber sábio (científico) possa fazer parte do seu cotidiano com significado. E, assim despertar nos estudantes a consciência de que o Sol é o responsável pela energia que rege a vida no planeta terra e as plantas são os "mediadores" dessa vida, pois capturam a energia luminosa e a transformam nas diferentes formas necessárias ao processo vital. Ao mesmo tempo, enfatizamse a representação das reações e das substâncias pela linguagem química e das transformações energéticas pela linguagem física.

\section{Considerações Finais}

A análise das sucessivas SE mostra potencialidades de significação do conceito energia de modo contextualizado permitindo que os estudantes ao longo do Ensino Fundamental se apropriem de aprendizagens sobre a caracterização da energia quanto: as suas formas, aos princípios de conservação, transformação e transferência. Esses conceitos iniciam seu uso e significação desde a $5^{\text {a }}$ série, o que permite seu desenvolvimento em níveis de complexidade evolutivo conforme pensamento de Vigotski (2000). É possível perceber a importância desse conceito na perspectiva da sustentabilidade, reconhecer que a energia garante a vida, as relações, os movimentos e o trabalho neste planeta. Nesse sentido, estar ciente quanto ao modo de uso desse bem vital, é de primordial importância.

Portanto, o conhecimento científico sobre a energia envolvida nos diversos contextos parece ter um papel fundamental na capacitação dos sujeitos em compreenderem o desenvolvimento sustentável no sentido de perceber a necessidade das contribuições individuais e coletivas. Esse conceito está presente em todos os níveis de ensino, numa variedade de fenômenos interdisciplinares, tais como: movimentos dos seres vivos; metabolismo; fotossíntese e respiração, em que as transformações da energia luminosa 
em química, potencial, cinética, e mecânica, por exemplo, são essenciais para a existência da vida na Terra, necessitando apenas serem (re)significados. O estudo do Sol como fonte natural dessa energia, que incide sobre a Terra, permite ao estudante visualizar e compreender a dependência da vida em relação à energia. Essa questão torna-se indispensável para a formação consciente no que diz respeito à Biologia da Conservação e a Sustentabilidade. É preciso estimular reflexões que atendam as questôes da sociedade moderna, tomando consciência de que a energia existente na natureza é a mesma para todos os processos, sejam biológicos, físicos ou químicos. Além disso, compreender que a energia é transportada, transformada, conservada e que seu uso precisa ser controlado, é importante para que cada sujeito possa atuar como cidadão, tomando decisões e agindo com responsabilidade social. Assim, a escola é o espaço instituído para trabalhar com o conhecimento formal, porém, não se trata apenas dos conteúdos, nem das objetivações como tais, mas com aspectos que relacionem os fenômenos vividos e sejam inseridos nas totalidades de suas participações. É necessário que esses conteúdos se constituam em aprendizagens escolares, provocadoras de variadas maneiras de pensar, que mudem e criem novas formas qualitativas de desenvolvimento intelectual das crianças e adolescentes. A aproximação dos currículos escolares das Ciências da Natureza e suas Tecnologias com situações reais contribuem para que os estudantes revistam de significados os conteúdos escolares produzindo sentidos para os conceitos científicos porque isso lhes possibilita compreender o mundo em que vivem. Nesse novo contexto, as situações de estudo propiciam aos estudantes tornarem-se "capazes de usar o conhecimento científico e tecnológico na solução de seus problemas no dia-a-dia; e a tomarem decisões com responsabilidade social" (SANTOS; SCHNETZLER, 1997; 1998). 


\section{Referências}

ANGOTTI, José. Fragmentos e totalidades no conhecimento científico e no ensino de ciências. Tese (Doutorado em Física) - Programa de Pós-Graduação: Instituto de Física - IFUSP e Faculdade de Educação FEUSP da Universidade de São Paulo. São Paulo, 1991. 265p.

ARAÚJO, Maria C. Pansera de; AUTH, Milton A.; MALDANER, Otavio A. A identificação das características de inovação curricular em ciências naturais e suas tecnologias através de situações de estudo. Bauru: Atas V ENPEC :1-12, CD-Rom, 2005

AUTH, Milton A. Conceitos unificadores e o ensino de ciências. Espaços da escola. Ijuí: Ed.Unijuí, ano 10, n. 38, p. 63-80, 2000.

AUTH, Milton; MELLER, Cléria (Orgs.). Ser humano: percepção e interação. Ijuí: Unijuí, 2005.

BRASIL. Ministério da Educação, Secretaria de Educação Média e Tecnológica. Parâmetros curriculares nacionais: ensino médio. Brasília: MEC/SE, 1999. 364p

. Ministério da Educação, Secretaria de Educação Média e Tecnológica. Parâmetros curriculares nacionais: ensino médio. Brasília: MEC/SE, 1998. 364p

BITTENCOURT, H. A matriz energética no desenvolvimento sustentável de pequenas propriedades rurais. Florianópolis/ SC: UFSC, Relatório de Conclusão de Curso, 2005. Disponível em: <http:/www.tcc.cca.ufsc.br/ agronomia/RAGR002.pdf>. Acesso em: 22 set. 2008

BOFF, Eva T. O; FRISON, Marli D.; KINALSKI, Alvina C. Evolução e níveis de compreensão do conceito substância na situação de estudo alimentos produção e consumo. In: MORAES, Ronaldo; MANCUSO, Ronaldo (Orgs.). Educação em ciências: produção de currículos e formação de professores. Ijuí: Ed Unijuí, 2004, p. 288-300.

BOFF, Eva T. O.; HAMES, C.; FRISON, M. D. (Org.) Situação de estudo alimentos: produção e consumo. Ijuí: Ed. Unijui, 2006. 88p.

CANTO, Eduardo Leite. do. Ciências naturais aprendendo com o cotidiano. São Paulo: Ed. Moderna, 1999. 
FABER, Daiane Thaise; SARTORI Flávia; ARAÚJO Maria Cristina P.; DALMAS Neiva Maria. O estudo de um empreendimento rural - a organização do espaço e dos recursos naturais: a experiência da escola municipal fundamental João Goulart. In: Encontro Investigação na Escola, 2004, Lajeado/RS. Anais do V Encontro Sobre Investigação na Escola. Ijuí: Univates, 2004, p. 1-3, CD-ROM.

FRONER, Daiana; BIANCHI, Vidica; WILENS, Viviane; ARAÚJO, M. Cristina Pansera-de. Fotossíntese e respiração: conceitos biológicos, físicos e químicos (re)significados na $8^{\mathrm{a}}$ Série do Ensino Fundamental. In: Encontro Regional Sul de Ensino de Biologia, 2006, Florianópolis/SC. Anais do II EREBioSul. Florianópolis/SC, 2006, CD-ROM.

GIPEC-Unijuí. Geração e gerenciamento dos resíduos sólidos provenientes das atividades humanas/GIPEC. Ijuí: Ed. UNIJUÍ, 2002. 60p. (Coleção situação de estudo: ciências no ensino fundamental).

OLIVEIRA, Sonia V. W. B. de L.; CALDO, Alexandre B.; MAGRINI, Glauco M. Geração de bioenergia e biofertilizante em propriedade rural eco-eficiente e sustentável. In: Encontro Nacional sobre Gestão Empresarial e Meio Ambiente, 2007, Curitiba/PR. Anais do IX ENGEMA. Curitiba: 2007, CD-ROM.

PANSERA-DE-ARAÚJO, Maria Cristina; FERREIRA, Francesca Werner; BIANCHI, Vidica. Situação de estudo: museu antropológico diretor Pestana e a colonização da região Noroeste do Rio Grande do Sul. In: VIII Encontro Perspectivas do Ensino de Biologia, 8. 2002, São Paulo. Anais do VIII EPEB. São Paulo, editora, 2002, CD-ROM.

REIS, Lineu Belico dos; SILVEIRA, Semida. (Orgs.). Energia elétrica para o desenvolvimento sustentável: introdução de uma visão multidisciplinar. 2 ed. São Paulo: Editora da Universidade de São Paulo, 2001. 288p.

SANTOS, Wildson Luiz Pereira dos; SCHNETZLER, Roseli Pacheco. Educação em química: compromisso com a cidadania. Ijuí: Editora da Unijuí, 1997.

SANTOS, Wildson Luiz Pereira dos; SCHNETZLER, Roseli Pacheco. Ciência e educação para a cidadania. In: CHASSOT, A.; OLIVEIRA, R.J. (Orgs.). Ciência, ética e cultura na educação. São Leopoldo: Editora Unisinos, p. 255-270, 1998. 
VYGOTSKY, Lev S. A construção do pensamento e da linguagem. São Paulo: Martins Fontes, 2001.

Programa nacional de educação e controle da poluição sonora programa silêncio. Disponível em: <http://www.ibama.gov.br/silencio/home.htm>. Acesso em: 20 ago 2008.

UNESCO - Disponível em: <http://www.unesco.org.br>. Acesso em: 20 jan. 2008. 